the samples he had been given had been recrystallised in recent times (Houtermans, F. G. in PotassiumArgon Dating, 5 Springer-Verlag; 1966). As a result the evaporite minerals have not subsequently been routinely employed for $\mathrm{K}-\mathrm{Ar}$ dating.

The apparent ease of escape of radiogenic daughter isotopes from salt formations, particularly in recent times, and the alarming implications in the event of a containment failure, seem to require a thorough re-evaluation of the stability of these beds. Before any final decision on high-level radioactive waste disposal is reached, a systematic programme of argon measurements might provide a simple means of determining the extent of this phenomenon and enable its significance to be assessed.

R. M. Macintyre

University of Strathclyde, Glasgow

\section{Alcohol in Britain}

Sir,--J. A. Spring and D. H. Buss's account of three centuries of alcohol in the British diet (Nature 270, 567-72; 1977) gives good evidence for the high intake of beer in Britain in years gone by. But may I add a comment to the statement that "there are no obvious reasons" for the steady decline in beer consumption during the eighteenth century (p 567)? It is that the increase in tea-drinking in that period was very much greater than taxation figures suggest.

Genuine China tea remained expensive throughout, but a great deal of what was consumed was in fact adulterated with the dried and chemically treated leaves of such trees as hawthorn, sloe and ash (known in the trade as 'smouch'), or with used tealeaves purchased at small cost from the kitchen-maids of the wealthy. The cheapest teas contained little else.

Tea-drinking increased steadily during the century in all classes of socicty, especially among women. For the poorest families in the South and Midlands, there was a reason for this increase. Enclosure and the high cost of fuel deprived them of soups and the cheapest cuts of meat, which required long cooking. Crude tea without milk was the only warm comforting element in a diet that otherwise consisted of bread, cheese and occasionally cold, fat bacon.

The changeover from beer to tea as the common mealtime drink was well under way during the 1730 s and 1740 s. And in 1784 the high import duty on tea was at last lowered to a nominal sum on the grounds that "tea has become an economical substitute to the middle and lower classes of society for malt liquor, the price of which renders it impossible for them to procure the quantity sufficient for them as their only drink".

\section{The Brotherton Library,}

$$
\text { C. Anne Wilson }
$$

Leeds

\section{Dietary lipids and heart disease}

SIR,--May I point out some fallacies in Dr John Rivers' review (Nature 270, 2; 1977 of the so-called 'lipid hypothesis' of coronary heart disease (CHD)?

-The Finnish trial of Miettinen et al did show a notable decrease in mortality for males on a diet relatively high in poly-unsaturated fat. During the transcription of the mortality data from the original paper (Miettinen et al, Lancet 2,$837 ; 1972)$ to the article discussed by your reviewer (Mann, G., N. Engl. J. Med. 297, 646; 1977) an error was made which obscures the difference in mortality between the experimental and the control period $(32.00+2.84$ does not equal 38.84 !). It is disappointing that neither the editor of the N. Engl. J. Med. nor your correspondent noticed this.

- Unlike cigarette smoking, atmospheric pollution has not been shown to be an independent risk factor for CHD. - Poly-unsaturated margarines do not necessarily contain trans fatty acids. The most popular Dutch brand of polyunsaturated margarines contains 60 to $65 \%$ cis-cis-linoleic acid and $0 \%$ trans fatty acids. Its British equivalent ('Flora') has $6 \%$ of its fatty acids as trans isomers, which is similar to the proportion found in butter (data by courtesy of Unilever Research, Vlaardingen, The Netherlands).

- Epidemiological data overwhelmingly point in the direction of a relation between consumption of saturated fat and CHD (Keys A., Atherosclerosis 22, 149-192; 1975). The Masai are only a notable exception. Incidentally it should be stressed that cause-effect relationships cannot be proved or disproved by such comparisons between tropical and western populations, but only by controlled experiments.

- Few people with original or heretic ideas in the food-health field are finding it really difficult to obtain research funds or publicity. Dr Mann himself, as the reccipient of a career investigatorship from the National Heart, Lung and Blood Institute, is a case in point.

Nutrition is a billion-dollar business, a favourite subject for the media and an almost religious pre-occupation for a large part of the public. In view of these pressures, scientists bear a heavy responsibility to keep their data straight. In my opinion neither Dr
Mann nor your correspondent have succeeded in this.

MartiJn B. Katan

The Agricultural University, Wageningen, The Netherlands

\section{Intelligence is more than IQ}

SiR,- - I was interested in the letter by Brian J. Ford (5 January, page 7). I agree very fully with him of course, that the controversy is confused by the impossibility of obtaining measurements independent of cultural background. It is a great pity that so much more ink is being spilt in trying to prove that the heredity factor is unimportant, which for all I know may be true, than in the effort to raise all cultural backgrounds to an optimum level.

1 would like to amplify $\mathrm{Mr}$ Ford's comment on the nced for producing criteria which would reconcile mental measurements with the realities of life. What is practically accepted as intelligence depends to a very much more limited extent on IQ than is usually recognised. Thus IQ measurements often depend largely on the accurate understanding of the exact meanings of words and on the solving of logical problems. Solving real practical problems may often involve no language at all and in nearly all cases is concerned with the realities of a complicated situation rather than with the exact words by which this should be described. Furthermore the problems presented are unnatural in that the examinee knows that he has all the data required and that every datum is correct.

In real-life problems one never knows in advance whether one has all the necessary data and often is unsure whether the available data are right. Practical intelligence is therefore concerned with the judgement of whether sufficient data are available, with an understanding of how to obtain fresh data when necessary and then assessing the correctness or otherwise of the vital parts of the data available. This will involve persistence-in few practical situations must one solve 12 problems in 36 minutes - an ability to avoid prejudice, and some capacity for lateral thinking as well as IQ. Having satisfactorily solved all the practical problems the logical problem is nearly always trivial.

While a high IQ is valuable in a number of ways and probably has some correlation with the other factors I have mentioned, it is most unfortunate that it is so widely regarded as more important than it is, merely because it is so easy to put it in numerical terms. J. H. Fremlin

The University of Birmingham, UK 